\title{
Linguagem cinematográfica como inscrição da marginalidade na produção de documentários brasileiros pós-1993 (1)
}

\section{Gustavo Souza}

\section{Resumo:}

A presença dos setores sociais vinculados diretamente ao contexto de marginalidade e violência urbana tem sido recorrente na produção de documentários brasileiros dos últimos anos. Entender este movimento requer voltarmos as atenções não apenas para os depoimentos que tratem do contexto social, econômico e urbano dos grandes centros brasileiros, mas também para o uso da linguagem cinematográfica como um recurso que materializa a condição marginal dos depoentes. Tal aspecto revela a importância do diálogo com outros gêneros audiovisuais para a apreensão desses elementos, que posteriormente revelarão uma possível "estética da marginalidade".

\section{Palavras Chave:}

documentário, linguagem cinematográfica, marginalidade.

\begin{abstract}
:
La présence des secteurs sociaux directement rattachés au contexte de marginalité et violence urbaine a été fréquente dans la production de documentaires brésiliens de ces dernières années. Comprendre ce mouvement exige qu'on se tourne non seulement vers les témoignages qui traitent du contexte social, économique et urbain des grands centres brésiliens, mais aussi vers l'utilisation du langage cinématographique comme ressource qui matérialise la condition marginale des témoins. Un tel aspect révèle l'importance du dialogue avec d'autres genres audiovisuels pour l'appréhension de ces éléments, qui révéleront ultérieurement une possible "esthétique de la marginalité".
\end{abstract}

\section{Keywords:}

documentaire, langage cinématographique, marginalité.

\section{Introdução}

O cinema brasileiro conheceu, a partir de 1993, uma fase que pouco tempo depois seria denominada de retomada. A escassez da produção que permeou os anos 80 se intensificou ainda mais no final desta década. Este panorama agravou-se após um decreto do então presidente Fernando Collor de Mello, que extinguiu em 1990 a Embrafilme - empresa pública responsável por boa parte do financiamento para a realização de filmes no país. Tal conjuntura viria a mudar após a renúncia de Fernando Collor à presidência, devido ao seu envolvimento em escândalos de corrupção amplamente divulgados pela mídia. Os governos posteriores empreenderam uma política cultural que possibilitaria a produção de filmes, a partir de leis cujos recursos viriam tanto do setor público como do privado (2). Esse novo cenário, então, contribuiu para o aparecimento do termo "retomada". 
Não podemos ignorar que o início dos anos 90 foi marcado por uma significativa pausa na produção de longas-metragens. Mas isso não nos impede de reconhecer que outros formatos cinematográficos, como o curta-metragem, por exemplo, continuaram a ser produzidos, mesmo com todas as dificuldades que caracterizam esse tipo de realização. Tomar a produção de cinema apenas como aquela de longas de ficção constitui um equívoco e, por conseqüência, reafirma o caráter limitado do termo. Por essa razão, usaremos a expressão pós-1993 quando nos referirmos à produção de cinema desse período. Não se faz necessário um prolongamento dessa discussão, uma vez que ela não é o cerne do nosso trabalho. A intenção é apenas registrar nosso posicionamento sobre uma determinada terminologia que se difundiu consideravelmente, sendo que, a partir do momento em que usarmos outra, é preciso esclarecê-la, para que se evitem desentendimentos.

Apesar de o cinema brasileiro ter "reiniciado" a produção a partir de 1993, a realização de documentários ganharia contornos mais definidos a partir do final da década de 90 e início dos anos 2000, período considerado por Xavier (2003: 163) como a "idade de ouro" do documentário, devido à qualidade em termos temáticos e estéticos. O pesquisador já havia chamado a atenção anteriormente para o fato de a produção pós-1993 ser marcada por uma independência estilística, algo não experimentado, por exemplo, nos anos 60 e 70 - período de uma produção intensa, que, por sua vez, estava dividida basicamente entre as propostas do cinema marginal e do cinema novo, que obedeciam a matrizes temáticas e, principalmente, estéticas bem definidas ( $c f$. XAVIER, 2001). A liberdade da qual fala Xavier está presente tanto na ficção como no documentário da "retomada".

Este período em que se "retoma" a produção de cinema no país é marcado também por uma presença significativa de filmes - documentários e ficções - que põem como personagens centrais pessoas diretamente vinculadas ao contexto de pobreza e violência urbana, seja como agentes, seja como vítimas. Este trabalho se debruça sobre as possibilidades de representação desses "setores marginais" ao tomar como ponto de partida a linguagem cinematográfica como estratégia narrativa e representacional.

Para nos ajudar no entendimento da questão, selecionamos dois documentários realizados a partir da segunda metade dos anos 90. São eles: $O$ rap do pequeno príncipe contra as almas sebosas (Paulo Caldas e Marcelo Luna, 2000) e Fala tu (Guilherme Coelho, 2003). O rap do pequeno príncipe... contrapõe as vivências de Hélio e Garnizé, nascidos e criados em Camaragibe (município pobre da Região Metropolitana do Recife). Hélio se torna justiceiro, cujo "trabalho" é eliminar estupradores, assaltantes e delinqüentes da convivência dos moradores do bairro onde mora. Garnizé, por sua vez, responde à violência com música e trabalhos sociais, atuando também na comunidade onde vive. Já Fala tu mostra o cotidiano de três rappers (3) cariocas que sonham em viver de música, mas, ao mesmo tempo, se deparam com uma realidade não favorável a esse desejo. Sabemos que no período da "retomada", há uma série de outros documentários que também possibilitam a discussão que queremos apresentar - Estamira (Marcos Prado, 2004), O prisioneiro da grade de ferro (Paulo Sacramento, 2003), Juízo (Maria Augusta Ramos, 2007), Serras da Desordem (Andrea Tonacci, 2006). Mas, para que possamos apreender os filmes de modo mais específico, decidimos estruturar o debate a partir dos documentários já citados.

\section{Em busca de uma "estética da marginalidade"}

A linguagem cinematográfica é um espaço de materialização de escolhas discursivas e representacionais. Entende-se por linguagem cinematográfica os componentes plásticos da imagem e a montagem, onde os elementos técnicos e estéticos se encontram para produzir um determinado sentido. O pesquisador Marcel Martin destaca que Griffith e Eisenstein são diretores bastante significativos, quando se considera a montagem o mais importante vetor da expressão fílmica ( $c f$. MARTIN, 2003: 16). Partimos da perspectiva de Martin com a intenção de apenas estabelecer um ponto de partida para discussão, pois um detalhamento de todas as correntes sobre linguagem e montagem nos conduziria a uma digressão pouco 
produtiva neste momento (4).

Os documentários escolhidos por este trabalho ilustram diferenciadas estratégias de linguagem. Voltaremos a essa questão mais adiante, por agora interessa-nos verificar a incorporação de outras linguagens audiovisuais nos documentários realizados pós-1993. Este tipo de apropriação é cada vez mais recorrente na produção de cinema, tanto de ficção como de documentários, e nos ajuda também a perceber como essa troca de referenciais interfere na constituição de uma estética da marginalidade e da violência no cinema.

Além da montagem, o diálogo com outros formatos audiovisuais permite o reconhecimento mais apurado dessa estética. Entre eles, destacam-se os elementos plásticos e narrativos do videoclipe. $O$ rap do pequeno príncipe contra as almas sebosas é um filme que aposta nessa possibilidade. Talvez o fato de um dos protagonistas estar diretamente vinculado à música facilite a inserção da linguagem do videoclipe no documentário. Em diversos casos, o videoclipe constrói uma história de forma não linear e fragmentada, pois sua narrativa preza muito mais pela experiência sensorial do espectador do que por um encadeamento lógico da seqüência que no final faça sentido. Aposta-se num intenso bombardeio de informações, imagens e sons, para que se construa muito mais uma sensação do que um modelo enunciativo facilmente identificável. É neste sentido que Ken Dancyger considera que o videoclipe ou, em sua nomenclatura, o estilo MTV, tem como propósito central a criação de um sentimento. Diz o autor:

O sentimento pode ser aguçado e profundo ou pode ser crescente e onírico. Em qualquer um dos casos, o estado cria um sentido desconectado para a narrativa. Devido à profundidade do sentimento de uma simples seqüência associada a um simples trecho da música, é difícil criar uma continuidade narrativa (DANCYGER, 2003: 195).

Nota-se que a fragmentação e a brevidade são elementos seminais para o videoclipe. $O$ rap do pequeno príncipe... parece levar essas características às ultimas consequiências. Em vários momentos, Garnizé, integrante da banda Faces do Subúrbio, é visto tocando bateria ou atabaque. Há um cuidado prévio para se obter uma imagem o mais plástica possível. A iluminação é planejada para pôr em evidência o músico, evitando-se o que muitos documentários fazem: captar a imagem com a luz natural. Os enquadramentos também são inusitados. Um deles capta o músico de cima para baixo, como se a câmera estivesse posicionada no teto. A assimetria das imagens remete às opções utilizadas pelo videoclipe. Essa estratégia também é percebida nas cenas de shows. É comum no meio musical a utilização de imagens de apresentações para se fazer clipe. Alguns alternam outras imagens com as da apresentação e outros fazem do show o próprio videoclipe. No caso de $O$ rap do pequeno príncipe..., o show da banda Faces do Subúrbio em um festival de música do Recife é incorporado no documentário. Talvez não haja forma mais eficaz de conhecer o trabalho da banda do que vê-la tocar, especialmente diante de uma platéia que está ali para isso.

Mas o momento em que fica mais latente a utilização de elementos do videoclipe para a inscrição da marginalidade é quando rappers dos grupos Racionais MCs e Faces do Subúrbio estão reunidos numa laje na periferia do Recife. Nesta passagem, o sentimento do qual fala Dancyger se torna evidente: o rapper Mano Brown aponta para as comunidades a sua volta e faz uma "adaptação" da periferia paulistana para a recifense. A intenção é mostrar que os bolsões de pobreza são iguais em todos os grandes centros urbanos. Em seguida, a câmera realiza um longo passeio aéreo pelo subúrbio do Recife. Neste momento, a música que acompanha as imagens traz a melodia da canção Glory Box, da banda britânica Portishead. A letra original em inglês, que fala do sofrimento amoroso de uma mulher, é substituída por uma lista de bairros da periferia de São Paulo, Rio de Janeiro e Belo Horizonte. Este videoclipe no meio da narrativa convida o espectador a constatar algo que já é notório, mas cuja real dimensão é melhor percebida com o recurso da imagem: os bolsões de miséria e pobreza são uma marca dos grandes centros urbanos. Bolsões 
que a cada dia se expandem e vêm a comprovar ano a ano o cerco da periferia por qual passam as grandes capitais brasileiras. Dessa forma, o foco desloca-se dos personagens para uma imagem que ajuda a construir um sentimento de alerta, em que não há mais como ignorar a presença da periferia e do periférico na dinâmica social da atualidade. Se a história até então era contada por Helinho e Garnizé, e pelos personagens a eles correlatos, a estética do videoclipe constrói uma nova possibilidade para o andamento da narrativa, ou como diria Dancyger (ibid., p. 204), "o estilo MTV subverte a experiência linear e valoriza a cena sobre a seqüência, um ato ou todo o filme". Como o videoclipe não apresenta um foco específico em sua narrativa, essa estratégia permite ao espectador a possibilidade de várias conclusões (se é que elas são possíveis ou necessárias).

\section{Hibridismo estilístico}

Dentre as possibilidades de linguagem, destacam-se as opções recorrentes no cinema direto e no cinemaverdade e suas influências no documentário brasileiro. As novidades temáticas e tecnológicas, contudo, não foram suficientes para que uma parte da produção abandonasse o viés institucional, tão caro à escola britânica dos anos 30, liderada por John Grierson. Nos documentários tomados como instrumentos para a educação social, a temática não ultrapassava o campo científico ou pedagógico, cuja amarração estética apresentava, basicamente, narração em off, imagens que confirmavam ou ilustravam o texto narrado e, quando havia, entrevistado falando para a câmera. Devido a tais convenções, filmes como $O$ homem da câmera (Dziga Vertov, 1929) só seriam classificados como documentários nos anos 60, quando a criatividade da qual falou Grierson (5) parece ter de fato emergido com o cinema-verdade e com o cinema direto. O surgimento dessas duas propostas representacionais não implicou, porém, o sepultamento por completo da influência do modelo britânico. Pelo contrário, ele ainda continuou a ser adotado por muitos documentaristas latino-americanos (BERNARDET, 2003; BURTON, 1990). Como aponta Renov, essa fixidez criou uma oposição entre ciência e arte, de tal forma que esta última por muito tempo permaneceu distante dos documentários, tanto em termos temáticos quanto estéticos. A aposta num modelo de linguagem mais "poético" sempre ocupou uma oposição à margem no campo documental, especialmente no período em que o griersonianismo exercia grande influência. No entanto, algumas propostas, anteriores à consolidação da escola britânica, já traziam a dimensão estética como elemento-chave (6). O tratamento criativo da realidade não precisa se divorciar dos recursos expressivos, sejam eles estéticos ou tecnológicos. Afinal, a partir do experimento é possível perceber as potencialidades de um determinado modelo representacional. Neste sentido, a dimensão estética precisa ser considerada, ou, como nos diz Renov (ibid.: 35),

O alvo comunicativo é freqüentemente realçado pela atenção à dimensão expressiva. O filme pode utilizar mais efetivamente as potencialidades de suas escolhas para conduzir idéias e sentimentos. Nessa direção, a função estética nunca pode estar completamente divorciada da função didática, que ainda pode apresentar resquícios do "prazer de aprender".

O documentário contemporâneo, mais do que nunca, parece estar atento a esta dimensão. A narrativa preza por novos matizes para a montagem e a fotografia, bem como utiliza outras formas de linguagem como a videoarte ou o videoclipe. Dissociado das regras do modelo temático e estético "clássicos", o documentário encontra espaço para transitar em esferas até então impensadas, indo além do "discurso da sobriedade" (NICHOLS, 1991), ou seja, o documentário como local específico para retratar temas como política, educação ou ciência. A produção brasileira, especialmente do final dos anos 90 em diante, tem demonstrado atenção a esse aspecto ao traçar uma nova configuração para a relação do documentário com o espectador. As inovações estéticas fazem o público se desprender de posicionamentos engessados, favorecendo um estreitamento com esse tipo de filme. Desse ponto de vista, o crescimento do interesse pelo documentário passa também pela maneira como ele lida e utiliza os recursos audiovisuais 
disponíveis a sua volta.

O hibridismo estilístico apontado por $O$ rap do pequeno príncipe... nos convida a verificar como o documentário Fala tu imprime questões de marginalidade na imagem. Partimos do pressuposto de que num filme a imagem é tão importante quanto o texto. Embora muitas análises privilegiem a fala dos personagens ou narradores, considerando o aspecto textual como o epicentro da narrativa fílmica e, portanto, o objeto a ser analisado, não podemos corroborar essa perspectiva quando estudamos a violência urbana e a marginalidade no cinema. A materialização dessas questões também se dá a partir de enquadramentos, fotografia e montagem, e vai além da questão texto/imagem, aliando-se também ao som, com a utilização da música.

Faz-se necessário atentar para o fato de que a linguagem cinematográfica também comunica. Dessa maneira, o termo "linguagem" deixa a esfera da abstração para também "falar", "dialogar", "comunicarse" com o espectador. Analisaremos separadamente alguns elementos da linguagem cinematográfica, mas isso não implica que eles sejam estanques e não dialoguem entre si. Pelo contrário, o entrecruzamento entre eles, em muitos casos, é crucial para o funcionamento do filme. A opção em separar cada item é fruto apenas de uma opção metodológica, que nos ajudará a entender como se estruturam, por exemplo, a montagem ou a fotografia.

Quando surgiu nos anos 60, o cinema direto (7) reivindicou para si a capacidade de mostrar a realidade sem qualquer possibilidade de intervenção. A câmera era posicionada diante de um acontecimento qualquer e a partir daí o diretor limitava-se a registrar, sem conversar com quem filmava, sem fazer perguntas. Este método de filmagem permitiu que cineastas como Frederic Wiseman, Richard Leacock e Robert Drew justificassem a captação da realidade em sua essência mais pura e original. Posteriormente esse argumento foi derrubado por pesquisadores e cineastas, pois a posição da câmera já implica uma escolha e, dessa forma, uma interferência diante do que se filma. Mesmo que não faça perguntas ao personagem filmado, o ângulo em que a câmera está situada já denuncia uma estratégia de enunciação.

O posicionamento da câmera na seqüência de abertura de Fala tu resgata traços do cinema direto. No início do filme, os personagens são apresentados. O primeiro deles é Toghun, que trabalha como representante comercial. A câmera o acompanha em direção ao trabalho: sair de casa, pegar o trem, visitar as lojas para oferecer os produtos que vende. O segundo personagem a ser mostrado é Macarrão. Antes de sua aparição, vemos anotações de jogo do bicho, para que em seguida ele apareça. É neste momento que o posicionamento da câmera difere do que foi utilizado para captar o primeiro personagem. Macarrão é filmado de longe, como se não tivesse sabendo que a filmagem está ocorrendo. Vemos que ele trabalha como passador de bicho. Combatente, a terceira personagem, é mostrada em seu local de trabalho - uma empresa de telemarketing. Ao contrário dos outros dois personagens, ela interage com a câmera quando pergunta se a equipe vai entrar com ela no banheiro.

Esta seqüência de abertura apresenta os personagens do filme, bem como o trabalho que lhes garante a sobrevivência. É interessante notar como o posicionamento da câmera se relaciona com esta questão. Toghun e Combatente desempenham atividades legais, e a câmera está próxima a eles. Já Macarrão, que trabalha no jogo do bicho (proibido por lei), é captado de forma "oculta". É como se a ilegalidade da atividade desenvolvida pelo rapper solicitasse um distanciamento, para que não se perdesse a naturalidade da prática. Esse posicionamento da câmera revela também uma ambigüidade: não temos como saber com exatidão se a intenção era captar as atividades da forma mais "real" possível ou se esta opção anuncia que o documentarista não compactua com o jogo do bicho, situando-se, portanto, distante. Dessa forma, o caráter marginal do personagem não se confirma apenas pelo fato de ele ser pobre e morador do morro, mas também por exercer um trabalho rechaçado pela lei. A ilegalidade, mais uma vez, insere na 
marginalidade quem a ela está diretamente vinculado.

A seqüência de abertura de $O$ rap do pequeno príncipe... apresenta um posicionamento da câmera que também merece ser destacado. Antes de apresentar os personagens, o documentário situa o espectador em relação ao local onde se passará a maior parte do filme, ou pelo menos de onde vêm seus protagonistas. Inicialmente há os planos do centro do Recife e seus prédios imponentes. A câmera é fixa, passeia por avenidas largas e iluminadas. O contra-plano acontece logo a seguir: o tranqüilo passeio, que acontecia no centro da cidade, dá lugar a uma câmera subjetiva trêmula e nervosa, que sugere uma fuga entre becos e ruelas mal iluminados. Se o centro ainda pode ser visto como um local aprazível, a periferia revela exatamente o contrário. A tranqüilidade cede lugar ao pânico, a beleza à feiúra, a luz à escuridão. $\mathrm{O}$ centro nos ajuda a ver que na margem a conjuntura é outra. A imagem tremida (provavelmente a câmera devia estar na mão) sugere uma tensão diante de um momento de risco ou perigo ocasionado por fuga ou perseguição. Neste caso, a câmera na mão é o selo que atesta a autenticidade e a verossimilhança das imagens.

O enquadramento feito pela câmera denota uma opção de comunicação que convida o espectador a construir diferentes formas de se relacionar com a imagem. Em documentários cujos personagens estão envolvidos em situação ilícita, é preciso considerar qual a melhor forma de captar o rosto para que a imagem não cause nenhum tipo de problema ou constrangimento posteriormente. Se tomarmos como exemplo documentários que, a partir de um efeito de computador, borram os rostos de depoentes que não podem ou não querem ser identificados (Notícias de uma guerra particular, João Moreira Salles e Kátia Lund, 1998, por exemplo), não se deixa de captar o depoimento e manter o anonimato. Borrar o rosto do jovem em situação ilegal, por exemplo, faz com que ele permaneça irreconhecível, mas, ao mesmo tempo, anula toda e qualquer possibilidade de percebermos as potencialidades do rosto, ou seja, sua expressão e sua identidade. O rosto não é apenas um espaço de funcionamento fisiológico, mas também um lugar de aparência, comunicabilidade e desejo; anulá-lo impede de verificarmos significações e subjetividades, condições indispensáveis para o que Deleuze e Guattari (1996) consideram rostidade, ou seja, uma multiplicidade que reafirma o valor da existência e cristaliza o rosto como uma máquina abstrata elaborada, que pode também se estender a outras partes do corpo dotadas de dimensão subjetiva e de significação. O homem não vive apenas como corpo físico, mas também a partir dos componentes subjetivos ou singulares adquiridos no convívio social e que, por conseqüência, determinam sua posição no mundo, ou como afirmam os autores "os rostos formam lugares de ressonância que selecionam o real ou o sentido" (1996: 32). Borrá-lo nos impede de verificar sua "eficácia de cifração" (1996: 42), pois o homem habita um corpo ao qual atribui significados e valores, com os quais se reafirma como pessoa no mundo.

Mas como apreender este aspecto sem comprometer a segurança e a privacidade do depoente? Uma saída seria o close no rosto, ou melhor, o superclose. Deleuze e Guattari consideram que o close no cinema teria duas funções: refletir a luz ou então acentuar as suas sombras até que se perceba todo o seu lado mais obscuro, menos visível (1996: 32). Em O rap do pequeno príncipe... percebemos que há uma aposta nesta segunda possibilidade. Os depoimentos da mãe de Helinho mostram enquadramentos em supercloses: olho, boca ou lábio. Assim, sua imagem permanece preservada, isenta de reconhecimento. O close no rosto materializa a significação e a subjetividade, da qual falam os autores, em enquadramentos que focam apenas em uma parte do lábio ou o olho, por exemplo. Mesmo com o superclose, percebemos a tristeza e a apreensão da mãe que pouco pode fazer pelo filho justiceiro. O rosto borrado afirma de forma imediata a condição marginal em que se encontra o entrevistado. O superclose também. Ambos asseguram a proteção, mas a segunda opção, além de evidenciar uma criativa possibilidade estética, atesta a singularidade de quem presta o depoimento. Os jovens e policiais que têm seus rostos apagados por um efeito de computação gráfica só poderão afirmar a sua presença por meio do depoimento que prestam. Anula-se, portanto, todo e qualquer potencial subjetivo que o rosto pode fornecer, o que certamente 
enriqueceria tanto a narrativa quanto ao fator estético do documentário.

Nos documentários analisados, nota-se que a fotografia não está relacionada apenas ao enquadramento, mas também à iluminação e ao tratamento que a imagem recebe posteriormente. Neste quesito, $O$ rap do pequeno príncipe... apresenta alguns momentos que merecem ser destacados. Falamos anteriormente das cenas em que Garnizé aparece tocando atabaque e bateria. Além de elas estarem bem próximas da linguagem do videoclipe, evidenciam um cuidado com a fotografia. A luz projetada privilegia o músico, de forma que o ambiente em volta se torna secundário. Os enquadramentos também são incomuns: tomados de cima ou diagonais, com uma câmera inquieta que se aproxima e se afasta do músico rapidamente.

Quando Garnizé fala sobre a capacidade de transformação da música, a imagem a seguir, mesmo sem texto, procura mostrar um caminho oposto ao da marginalidade. Um dos pontos altos deste momento é quando uma montagem paralela intercala depoimentos de Garnizé e de outros justiceiros que falam dos critérios adotados para eliminar uma suposta "alma sebosa", entre eles a tatuagem. A seguir, vemos um tatuador terminar uma tatuagem com a imagem de Che Guevara nas costas de Garnizé. A câmera percorre seu corpo e mostra outras duas tatuagens do músico: Martin Luther King e Malcom X. A luz utilizada privilegia as tatuagens de Garnizé. Esta seqüência põe em xeque o discurso dos justiceiros, ao mostrar que pessoas "de bem" também podem ter tatuagens. Neste caso, fotografia e montagem se articulam para mostrar que o envolvimento com o crime é uma alternativa a ser repensada e que a regeneração, mesmo que pareça distante, é possível (8). Isso nos leva a pensar, com Bill Nichols (1993: 175), a possibilidade do "corpo como testemunha", facilitado pelo o que o autor considera performance virtual, isto é, o momento em que os atores sociais representam eles mesmos, sem utilizarem os recursos típicos da performance tradicional.

O deslocamento do conceito de performance privilegia o não planejado, o que está fora do script, algo que o cotidiano ajuda a construir. Para isso, é necessário que o documentarista veja no inesperado a possibilidade do acontecimento fílmico. Além disso, tal procedimento abala as estruturas de um possível modelo convencional para o documentário. Nessa direção, o corpo no documentário ajuda a construir sistemas de representação, ficando para segundo plano o caráter de ilustração ou personificação de um fetiche. O corpo se torna o veículo de apresentação de si, pois é dotado de imaginário e identidade, e contribui para o desenrolar da narrativa, pois "a dor, a dúvida, o orgulho e o conhecimento não podem estar separados do corpo onde eles residem” (1993: 187).

Um outro momento em que a fotografia atua de forma peculiar no documentário $O$ rap do pequeno príncipe... é na seqüência em que Garnizé fala da experiência de viver no Recife. Durante o depoimento, seu rosto é captado de perfil, com a cidade ao fundo. Em alternância a Garnizé, o documentário mostra imagens de skatistas atravessando pontes e avenidas movimentadas do centro da cidade. Neste momento, há uma alternância do foco que muda de acordo com o que é dito. Quando Garnizé fala sobre o Recife, seu rosto fica embaçado, em segundo plano, e a cidade ao fundo surge na tela como a imagem principal. Quando o músico fala de suas experiências pessoais, acontece o inverso, o foco permanece em seu rosto de perfil, e a cidade, em segundo plano. Os recursos de linguagem, neste caso, tornam-se mais eficazes do que o depoimento, e nos chamam a atenção para as adversidades sociais a que os setores marginalizados estão submetidos. Uma questão urgente, mas que ainda é vista e tratada como se fosse secundária. Nos momentos finais de A linguagem cinematográfica, o pesquisador Marcel Martin afirma que a salvação do cinema estará guardada enquanto houver experimentalismos e quem busque novas rotas e itinerários. Se esse é o caminho para a continuidade da experiência cinematográfica, a produção brasileira de documentários parece cumprir o seu papel. 


\section{Bibliografia:}

BAZIN, André. O cinema: ensaios. São Paulo: Brasiliense, 1991.

BERNARDET, Jean-Claude. Cineastas e imagens do povo. São Paulo: Companhia das Letras, 2003.

BURTON, Julianne. "Towards a history of social documentary in Latin America". In: BURTON, Julianne (org.). The social documentary in Latin America. Pittsburgh: University of Pittsburgh Press, 1990.

DANCYGER, Ken. Técnicas de edição para cinema e vídeo. São Paulo: Campus, 2003.

DELEUZE, Gilles \& GUATTARI, Félix. Mil Platôs - capitalismo e esquizofrenia. Vol. 3. Rio de Janeiro: Editora 34, 1996.

MARTIN, Marcel. A linguagem cinematográfica. São Paulo: Brasiliense, 2003.

NICHOLS, Bill. Representing reality. Bloomington: Indiana University Press, 1991.

. “'Getting to know you...': knowledge, power, and the body”. In: RENOV, Michael (org.). Theorizing documentary. Nova York: Routledge, 1993.

RENOV, Michael. "Towards a poetic of documentary". In: RENOV, Michael (org.). Theorizing documentary. Nova York: Routledge, 1993.

ROTHA, Paul. Documentary film. Londres: Faber and Faber, 1936.

XAVIER, Ismail. "Documentário e afirmação do sujeito: Eduardo Coutinho na contramão do ressentimento". In: CATANI, Afrânio Mendes et alii (orgs.). Estudos socine de cinema. Ano IV. São Paulo: Panorama, 2003.

. O cinema brasileiro moderno. São Paulo: Paz e Terra, 2001.

\section{Notas:}

(1)Trabalho apresentado no NP de Comunicação Audiovisual do XXXI Congresso Brasileiro de Ciências da Comunicação (Intercom), realizado de 2 a 6 de 2008 de setembro em Natal(RN).

(2) Entre essas leis estão a Lei de Incentivo à Cultura (1991) e a Lei do Audiovisual (1993). Ambas permitem a empresas públicas e privadas a dedução no imposto de renda, se o dinheiro for destinado a produção de filmes e outros formatos audiovisuais.

(3) Rapper é o cantor (e compositor) das músicas do movimento hip-hop. Por se repetir de forma constante neste trabalho, os termos, mesmo de origem estrangeira, serão grafados sem destaque.

(4) Cineastas como Vertov e Pudovkin também apresentam posicionamentos definidos sobre a montagem e sua relação com o documentário. Pudovkin concebia a montagem no esquema "tijolo a tijolo", resultando numa narrativa linear. Já Vertov via no documentário o único formato capaz de retratar a realidade e, dessa forma, atingir/educar o espectador. Dentro desse horizonte, não se pode desconsiderar 
também o posicionamento de André Bazin (1991). Embora não despreze o potencial e a importância da montagem, a crítica de Bazin ao modelo da escola russa, em especial a Eisenstein, salienta que a montagem realizada pelos soviéticos atendia a necessidades que não eram especificamente cinematográficas.

(5) Grierson definiu o documentário como um gênero cinematográfico capaz de elaborar o "tratamento criativo da realidade" ( $c f$. ROTHA, 1936: 70).

(6) Renov cita alguns exemplos: entre eles estão Nanook, o esquimó (1922), de Robert Flaherty, o ciclo de "sinfonias" sobre as metrópoles que começou em Berlim nos anos 20 e se espalhou pelo mundo, além do documentário Rain (1929), de Joris Ivens, $c f$. RENOV, 1993: 33.

(7) De acordo com a classificação de Bill Nichols (1991), equivale ao modelo de observação.

(8) Nesse depoimento, Garnizé cita o exemplo de Malcom X que, segundo o músico, tinha sido traficante e gigolô, e depois mudou o rumo de suas ações.

\section{Mini Currículo :}

Doutorando em Ciências da Comunicação pela ECA/USP. Mestre em Comunicação e Cultura pela ECO/UFRJ. Formando em Comunicação Social/Jornalismo pela UFPE. 